\title{
Public Health Disaster Research: Surveying the Field, Defining Its Future
}

by David M. Abramson, PhD, MPH, Stephen S. Morse, PhD, Andrew L. Garrett, MD, MPH, and Irwin Redlener, MD

$\mathrm{D}$ isaster medicine and public health preparedness are commonly perceived as subfields of the larger fields of medicine and public health rather than being recognized as an emerging academic field embracing all of the disciplines that contribute to effective disaster response. As such, they serve as appropriate subjects for multidisciplinary work in the social sciences, whether it is a sociological analysis of mass behavior during a disaster, psychological studies of the willingness to work of various workforces, or organizational theory or network analyses applied to ad hoc disaster coalitions. Laboratory sciences and bioinformatics contribute as well to the development of new treatment modalities, medical products, and surveillance technologies. As is true in the broader medical and public health fields, much of the work is empirical and evaluative. In this article, the authors survey the literature in the field and suggest that broader, more ecologically based research is needed.

\section{METHODS}

To survey the current state of the research methodology, the authors conducted a literature review of all medical and public health journals from January 2002 through the present for English-language articles containing the phrases "disaster medicine" or "public health preparedness" in the title, subject, body, or as key words. The search was conducted using both MEDLINE and PubMed databases, and all duplicates were removed. In addition, all of the articles from the journal Prehospital and Disaster Medicine were included in the analysis, regardless of whether they met the inclusion criteria noted above. Articles excluded were editorials, letters to the editor, or conference abstracts, as well as any articles that focused solely on an emergency medicine or prehospital issue that was not disaster-related. A total of 303 articles were identified. Two of the authors (D.M.A. and A.L.G.) reviewed and coded all of the records independently. All coding discrepancies were discussed and reconciled through a consensual process.

All of the articles were coded by the type of research methodology used (eg, survey, secondary data analysis, clinical trial, case study), the primary research objective (eg, descriptive, epidemiological or health services research, evaluation research, guideline development, hypothesis-testing, organizational or policy planning), the primary unit of analysis (eg, individual, organizational, social or communal-level, or political/legal/ethical frameworks), and the primary hazard phase being addressed by the research (eg, prevention or mitigation, preparedness, response or event-phase, short- or long-term recovery). As a group, these selected articles represent the core disciplinary literature in the evolving fields of disaster medicine and public health preparedness.

\section{RESULTS}

A majority of the articles reviewed were based on qualitative data, reviewed common disaster-related practices or strategies, or presented conceptual frameworks (Table 1). One third of the articles surveyed were review articles and another one fourth were based on case study research; fewer than one third were based on quantitative analyses, and the majority of those were descriptive surveys. A number of the surveyoriented articles reported on questionnaires directed at medical and public health disaster workers to evaluate or determine the efficacy of a training protocol or to establish opinion about existing or proposed disaster response practices. Training was discussed or mentioned in 80 of the 303 abstracts included for review, suggesting a widely acknowledged interest in the skills and knowledge required for the evolving science of disaster medicine. ${ }^{1-3}$

In line with the methodology employed in the majority of the research articles, most of the literature was either descriptive $(36.0 \%)$ or oriented toward organizational development or policy planning (25.1\%; Table 2). Frequent topics included disaster response and recovery system improvement, as well as the need to develop cross-jurisdictional or nontraditional partnerships. ${ }^{4-7}$ A small proportion of the literature was devoted to epidemiological and health services analyses $(11.9 \%)$, which generally characterized the nature and types of injuries encountered in disasters or patterns of service utilization trends. ${ }^{8-13}$ An additional 20\% of the literature focused on evaluating programs and policies, described or proposed operational guidelines or protocols, or reported on needs assessments principally related to workforce and organizational capacity. A small percentage of the research literature used advanced study designs, such as clinical trials or quasiexperimental methods ( $8.9 \%$ ), and even fewer used such methods in hypothesis-driven studies (5.3\%).

The unit of analysis for three fourths of the literature was either the individual or an organization (Table 3). Furthermore, when viewed along the hazard-phase continuum (prevention/ 


\section{TABLE 1}

\section{Research Methodology Used in Disaster Medicine and Public Health Preparedness Research Literature $(\mathbf{n}=$ 303 Articles, January 1, 2002-March 10, 2007)}

\begin{tabular}{lrr} 
& $\mathbf{n}$ & $\%$ \\
Review/commentary & 98 & 32.3 \\
Case study & 74 & 24.4 \\
Survey & 37 & 12.2 \\
Program or policy evaluation & 25 & 8.3 \\
Quasiexperimental/observational & 20 & 6.6 \\
Secondary data/administrative data analysis & 20 & 6.6 \\
Key informant interviews/consensus & 12 & 4.0 \\
Clinical trial & 7 & 2.3 \\
Epidemiological investigation & 6 & 2.0 \\
Operational research/computer modeling & 3 & 1.0 \\
Focus group & 1 & 0.3 \\
\hline
\end{tabular}

mitigation $\rightarrow$ preparedness $\rightarrow$ response $\rightarrow$ recovery), most of the articles focused on either preparedness (44\%) or on the event and response itself (39\%). Taken together, two thirds of the research literature analyzed or reported on preparedness or response from the perspective of individuals (whether providers or patients) or organizations. Only $4 \%$ of the articles addressed questions of prevention or mitigation, and only $13 \%$ focused upon issues related to short-term or long-term recovery.

\section{DISCUSSION}

As in many professional fields, the research in disaster medicine and public health preparedness closely follows federal program funding streams and policy initiatives. Since the passage of the Public Health Security and Bioterrorism Preparedness and Response Act of 2002 more than US $\$ 5$ billion has been spent on public health preparedness activities associated with workforce development, enhancing organizational capacity, standardizing emergency procedures, and promoting individual and community-level preparedness. ${ }^{14}$ Much of the current research literature represents efforts to evaluate these activities. There is a greater emphasis on process evaluations, such as the effect of a specific training program on increasing a particular knowledge base, than on outcome evaluations such as whether a specific knowledge area is associated with improved disaster response. ${ }^{15}$

Given the organizational complexities involved in preparing for and responding to various disasters, and the fact that the fields of disaster medicine and public health preparedness are relatively young, it is to be expected that much of the literature highlights the narrow band just before and after the events. One would anticipate that as these fields mature and organizational strategies are more thoroughly tested and evaluated, the focus will naturally broaden to the social and political levels and the prevention and recovery phases, which may prove essential in ensuring the most positive outcomes. This review of the literature does suggest a number

of challenges facing public health disaster research, as well as opportunities for future research areas and methodologies.

\section{Challenges}

Health-related disaster research poses challenges ranging from study design problems to logistical issues. Methodologically, there is an inherent problem of a small number of cases, and rarely an opportunity to standardize data collection efforts to allow for a comparative case approach, much less meta-analyses. Inasmuch as prospective research designs are difficult to develop, the field must generally rely on observational and quasiexperimental research designs. This presents its own challenge: If each disaster case is "exceptional" in its own way, as a complex interaction of hazard, geography, response system characteristics, and vulnerable populations, then it is difficult to identify meaningfully consistent variables from which to generalize and theorize.

There is also a considerable challenge in the field to develop methods for testing the empirical basis of disaster practices, such as laboratory simulations, computer modeling, and operational research, which could then be incorporated into training and educational curricula.

A number of other "process" issues confront public health disaster research. Foremost is the need for rapid funding mechanisms and the training and deployment of research field teams, particularly if there is an interest in obtaining data during the response or short-term recovery phases. Community-based disaster research is often labor intensive. Furthermore, there are issues of institutional review board processes, including both time factors and the tendency of many institutional review boards to regard all disaster victims as a vulnerable population for whom any research may be viewed as a "risky and burdensome enterprise" requiring special attention and consent. ${ }^{16}$ Of course, these issues have less salience if the research is conducted during a predisaster period or considerably after the fact.

\section{Untilled Research Fields}

The fields of disaster medicine and public health preparedness may be defined broadly or narrowly circumscribed. The

\section{TABLE 2}

\section{Primary Research Objectives of Disaster Medicine and Public Health Preparedness Research Literature $(\mathrm{n}=$} 303 Articles, January 1, 2002-March 10, 2007)

Descriptive

Organizational/policy planning or development

Epidemiology/health services research/service utilization

Evaluation research

Guideline, algorithm, or protocol development

Hypothesis-driven

Needs assessment

Other n $\%$

10936.0

$\begin{array}{ll}76 & 25.1\end{array}$

$\begin{array}{ll}36 & 11.9\end{array}$

$\begin{array}{ll}24 & 7.9\end{array}$

$24 \quad 7.9$

$\begin{array}{ll}16 & 5.3\end{array}$

$15 \quad 5.0$

31.0 
Proportion of Research Literature Categorized by Analytical Unit and by Hazard Phase ( $n=303$ Articles, January 1 , 2002-March 10, 2007)

\begin{tabular}{|l|ccccc|} 
& & & & 0.00 & \\
Political/legal (14\%) & 0.33 & 9.24 & 3.63 & 0.33 & 1.65 \\
Social (10\%) & 0.99 & 3.63 & 3.30 & 1.65 & 0.00 \\
Organizational (44\%) & 0.99 & 24.75 & 16.17 & 6.60 & 1.65 \\
Individual/clinical (33\%) & 1.65 & 6.60 & 16.17 & Short-term recovery & Long-term recovery \\
& Prevention/mitigation & Preparedness & Event/response & $(9 \%)$ \\
\hline
\end{tabular}

widest landscape would encompass research that examines the social forces that predispose some people and groups to be more acutely vulnerable to specific hazards, and would also consider the policies that could prevent the hazards from occurring or that could mitigate the consequences of any specific threat. Furthermore, the consequences of a disaster do not end once the environment has been stabilized and all critical injuries have been attended to. A community's recovery has significant health and medical components, in terms of the chronic health conditions of the population, the availability and quality of health services, the capacity to promote healthful activities and sustain preventive behaviors, and the overall ability of the affected community to reconstitute its health system and allied services.

A narrower definition of the field, however, would focus on preparing health sectors for various disasters, identifying event-specific screening and treatment modalities, and designing systems of care for responding to and treating the affected populations. Using this calculus, prevention and mitigation are generally beyond the scope of disaster medicine and public health preparedness, as are issues of long-term recovery.

Although it is critical that public health and medical systems maximize their ability to prepare and respond to disasters, we believe that the broader view is essential to developing knowledge and interventions that lead to enhanced population resiliency and survival. Research should be considered within an ecological framework that incorporates multiple levels, from the individual through the organizational, social, and political realms, an agenda similar to that proposed by the National Institutes of Health in its report on integrating social and cultural dimensions into multilevel analyses of health. ${ }^{17}$ Figure 1 illustrates some of the research areas in a matrix comparing units of analysis (individual, organizational, social, political, legal) for each hazard phase. This listing is not intended to be comprehensive, but rather to stimulate thought as to what research questions could be posed within each cell. For example, within the prevention and mitigation phase, in which the potential consequences of any disaster could either be averted or greatly buffered, a research team may consider whether enhancing self-sufficiency among vulnerable individuals would lead to greater resiliency, emergent leadership, and quicker recovery in the face of a disaster. A political analysis could explore the ethics of mass vaccination in the context of a high-risk/low-probability event.

Within the preparedness phase, there is a considerable need for outcomes research. Although federal campaigns exhort individuals to "Get a kit, make a plan, and be informed," 18 there is little empirical evidence to suggest which elements, if any, of the kit, plan, or information are associated with improved outcomes or a reduced burden on the response system.

Within the response phase there is an emerging literature about nonpharmaceutical interventions such as school closures and social distancing in response to a pandemic influenza outbreak, but less emphasis on the unanticipated consequences of such policies. Long-term school closures could lead to major workforce shortages, nutritional concerns if students are unable to access free breakfast and lunch programs, and an increase in youth risk behaviors if many are unsupervised. For legal and ethical frameworks during the response phase, some compelling topics include appropriate modifications of standards of care, resource allocation principles, revised triage protocols, and cross-border access and treatment concerns.

The recovery phase after a disaster is composed of short-term and long-term recovery components, which lack a clear demarcation between them. From a population perspective, there may be a defined role for ancillary services such as case management to support medical home models similar to those that have evolved in domestic HIV/AIDS programs. Furthermore, from a political and legal standpoint, a valuable research initiative would be an examination of disaster relief policies (eg, disaster-relief Medicaid, Robert T. Stafford Disaster Relief and Emergency Assistance Act provisions, HIPAA waivers) and their contribution to enhancing medical care access and health outcomes.

Although the progression of stages illustrated in Figure 1 is linear, one can easily imagine these stages as a circular process. Long-term recovery activities may lead to new prevention and mitigation efforts. Policies clearly affect individuals and organizations. It would be useful to apply multilevel modeling techniques, such as hierarchical linear regression models, that could accommodate these multiple domains and effects. 


\begin{tabular}{|c|c|c|c|c|c|}
\hline $\begin{array}{r}\text { Political } / \\
\text { Legal / Ethical }\end{array}$ & $\begin{array}{l}\text { Cost-benefit analyses; } \\
\text { reviewing regulatory } \\
\text { policy instruments; } \\
\text { vaccine development } \\
\text { strategies; mass } \\
\text { vaccination ethics }\end{array}$ & $\begin{array}{l}\text { Vulnerable population } \\
\text { registries; governance } \\
\text { issues of shared } \\
\text { authorities; extent and } \\
\text { efficacy of public } \\
\text { health police powers }\end{array}$ & $\begin{array}{l}\text { Modified standards of } \\
\text { care, triage and } \\
\text { allocation standards; } \\
\text { fiability \& professional } \\
\text { credentialling; cross- } \\
\text { border access and } \\
\text { treatment issues }\end{array}$ & $\begin{array}{l}\text { Disaster-relief } \\
\text { Medicaid; waiver of } \\
\text { regulations } \\
\text { (HiPAA, workforce } \\
\text { rules) }\end{array}$ & $\begin{array}{l}\text { Defining when } \\
\text { "disaster relief" } \\
\text { ends and social } \\
\text { assistance begins }\end{array}$ \\
\hline $\begin{array}{r}\text { Social/ } \\
\text { population }\end{array}$ & $\begin{array}{l}\text { Analyzing effect of } \\
\text { social, economic, } \\
\text { linguistic vuinerabilities } \\
\text { on disaster outcomes }\end{array}$ & $\begin{array}{l}\text { Developing } \\
\text { surveillance tools and } \\
\text { trigger points for } \\
\text { medicat and public } \\
\text { health response }\end{array}$ & $\begin{array}{l}\text { Unanticipated } \\
\text { consequences of } \\
\text { public health } \\
\text { interventions }\end{array}$ & $\begin{array}{l}\text { Role of social } \\
\text { services (housing, } \\
\text { education, } \\
\text { community re- } \\
\text { engagement) in } \\
\text { limiting physical } \\
\text { and mental health } \\
\text { sequlae }\end{array}$ & $\begin{array}{l}\text { Long-term recovery } \\
\text { as a form of local } \\
\text { system and } \\
\text { community } \\
\text { development }\end{array}$ \\
\hline Organizational & $\begin{array}{l}\text { Physical hardening of } \\
\text { facilities; value of } \\
\text { nomalizing ongoing } \\
\text { collaboration among } \\
\text { sectors }\end{array}$ & $\begin{array}{l}\text { Workforce training } \\
\text { and poilicies to assure } \\
\text { willingness and ability } \\
\text { to work during a } \\
\text { disaster }\end{array}$ & $\begin{array}{l}\text { Systems for } \\
\text { coordinating private } \\
\text { medical and public } \\
\text { health activity; } \\
\text { emergent referral } \\
\text { networks }\end{array}$ & $\begin{array}{l}\text { Development of } \\
\text { shared data } \\
\text { systerns (health } \\
\text { records, pharmacy } \\
\text { records) }\end{array}$ & $\begin{array}{l}\text { Maintaining stable } \\
\text { public health } \\
\text { functions if } \\
\text { workiorce and } \\
\text { system have been } \\
\text { severely disrupted }\end{array}$ \\
\hline \multirow[t]{2}{*}{$\begin{array}{r}\text { Individual / } \\
\text { Clinical }\end{array}$} & $\begin{array}{l}\text { Deveiopment of tailored } \\
\text { preventive health } \\
\text { messages for } \\
\text { vulnerable patients by } \\
\text { enhancing self- } \\
\text { sufficiency }\end{array}$ & $\begin{array}{l}\text { Outcomes research } \\
\text { on value of individual } \\
\text { preparedness in } \\
\text { reducing system } \\
\text { burden }\end{array}$ & $\begin{array}{l}\text { Treatment efficacy } \\
\text { and protocol studies; } \\
\text { matching responder } \\
\text { capacity to need }\end{array}$ & $\begin{array}{l}\text { Disaster-based } \\
\text { orimary care: } \\
\text { defining the } \\
\text { evolution of } \\
\text { emergency to } \\
\text { primary care }\end{array}$ & $\begin{array}{l}\text { Estimating the } \\
\text { long-term physical } \\
\text { and mental health } \\
\text { impacts of disaster }\end{array}$ \\
\hline & $\begin{array}{l}\text { Prevention + } \\
\text { Mitigation }\end{array}$ & Preparedness & Response & $\begin{array}{l}\text { Short-term } \\
\text { recovery }\end{array}$ & $\begin{array}{l}\text { Long-term } \\
\text { recovery }\end{array}$ \\
\hline
\end{tabular}

Fundamental to all of these potential research topics is the questioning of assumptions, a critical reluctance to accept the received wisdom. Is the way in which we have organized our response systems to respond to emergencies, using such hierarchical structures as the Incident Command System, the most adept at dealing with complex emergencies? Russell Dynes, the founding director of the Disaster Research Center, has long noted the differences between "military model" response structures, such as that embodied by the Incident Command System and the National Incident Management System, and more nimble "problem-solving" models, which are closer to collaborative public health strategies. ${ }^{19}$ Louise Comfort, a veteran disaster researcher, has noted that "building networks of organizations committed to a process of continual inquiry, informed action, and adaptive learning is a more flexible, robust strategy than the standard practice of establishing greater control over possible threats through administrative structures." ${ }^{20}$ It is likely that a blending of the models may be most effective. Research, if done properly, could inform practice.

One recent advance has been the promotion of an Utstein Framework for evaluation and research of disaster-related health events, ${ }^{21}$ modeled on cardiopulmonary resuscitation research. This field, like disaster research today, had been plagued by a lack of standardized terminology. ${ }^{22}$ Much as an epidemiological case definition standardizes the clinical identification of an infectious disease, the Utstein Framework standardizes the case description of a disaster, allowing researchers to devise various methods of comparative case analyses, including post hoc regression models, or to develop meta-analyses. Even more innovative techniques could in- clude a variation of Ragin's comparative case methodology, which uses Boolean algebraic truth tables to permit case comparisons rather than variable-level comparisons conventionally used in multivariate analyses. ${ }^{23,24}$ Depending on the particular research question there are also opportunities to capitalize on larger numbers of cases by focusing on health systems, public health departments, or governmental jurisdictions such as counties at which much emergency management is organized. Prospective studies could then use research strategies such as randomized cluster designs, whereas observational and retrospective studies could benefit from a number of sampling strategies.

Qualitative studies, in general, can offer much to the nascent research field. Oral histories and detailed ethnographic and participant-observation studies can provide rich detail on social and organizational processes for which there are no quantitative datasets. Qualitative research can inform theory generation; prove (or disprove) quantitatively deduced hypotheses; and engage the research, practice, and policy worlds through the strength of its narrative. Case study methods, for example, can be as rigorous as the most complex quantitative design. ${ }^{25-27}$

\section{CONCLUSIONS}

Necessary Partnership of Medicine and Public Health In some ways disaster medicine and public health preparedness in the 21st century mirrors that of the late 19th century, when physicians and public health officials found themselves constant allies rather than occasional colleagues. ${ }^{28,29}$ The factors that made 19th century populations particularly vul- 
nerable to infectious agents were inherently social: overcrowding, economic disparities, poor housing, poor nutrition, and inadequate safety regarding water and sewage systems. Similarly, many disaster threats faced today, whether caused by anthropogenic or natural hazards, have a social rather than clinical etiology, broadly encompassing population growth, economic imbalances, cultural tribalism, emerging infectious agents, or chemical or nuclear agents. ${ }^{30}$ Many of the consequences of the devastation wrought by Hurricane Katrina-failed sewage pumps, rotting food stocks, and the need for mass vaccinations, mortuary services, primary medical care for special needs populations, and even durable medical equipment for chronically ill populations-fell to public health. The private medical community was the first among many partners that public health had to recruit for its response and recovery missions.

In testimony before the US Congress in 1996 former Federal Emergency Management Agency administrator James Lee Witt noted that "All disasters are political." Although the direct provision of medical care during a disaster may not seem like a political act, the environment that precedes and succeeds that clinical encounter is informed by politics and policies. Policymakers shape the landscape that will influence the nature of mitigation, preparedness, response, and recovery for any domestic population or hazard event. If public health disaster research intends to be translational, then its scope should span the multiple layers of ecological units and hazard phases, and its primary audiences must include not only providers, planners, and researchers but also policymakers.

\section{Study Limitations}

The literature review conducted for this study captured a cross-section of relevant research articles in the medical and public health journals. In an effort to focus on the core public health disaster research literature, the authors elected to purposefully limit the search by language, time frame, and journal databases. Future studies should expand such reviews to non-English language journals to include the larger international literature. Also, a broader key word search within a longer time period will likely result in sufficient numbers to allow for trend analyses, particularly among categorical subgroups. The search would also be enriched by including other literatures, such as those of the social sciences and public administration. An analysis of citations could suggest the level of cross-disciplinary interest in the field.

The medical and public health journals from which this literature survey were drawn represent the most common sources of research and data for health-oriented practitioners and researchers in the field. The disaster literature has been scattered over journals in a variety of fields and disciplines, but are often not used by researchers in disaster medicine and public health because of the difficulty of identifying them. Until recently, there have been few journals covering the full spectrum of disaster research. This fragmentation of knowledge, and difficulties in integrating and applying results and methodologies from other disciplines has been a serious limitation in the development of the field of public health disaster research.

\section{About the Authors}

David M. Abramson is Director of Research, Stephen S. Morse is an associate professor of clinical epidemiology and founding director of the Center for Public Health Preparedness, Andrew L. Garrett is Director of Preparedness Planning and Response, and Irwin Redlener is Director of the National Center for Disaster Preparedness and Associate Dean for Public Health Advocacy and Disaster Preparedness, Mailman School of Public Health, Columbia University.

Received for publication March 27, 2007; accepted March 29, 2007.

ISSN: 1935-7893 (C) 2007 by the American Medical Association and Lippincott Williams \& Wilkins.

DOI: 10.1097/DMP.0b013e318065b7e1

\section{REFERENCES}

1. Tice AD, Kishimoto M, Dinh CH, Lam GT, Marineau M. Knowledge of severe acute respiratory syndrome among community physicians, nurses, and emergency medical responders. Prehospital Disaster Med. 2006;21 (3):183-189.

2. Horney JA, MacDonald P, Rothney EE, Alexander LK. User patterns and satisfaction with on-line trainings completed on the North Carolina Center for Public Health Preparedness Training Web Site. J Public Health Manag Pract. 2005;Suppl:S90-S94.

3. Alexander GC, Larkin GL, Wynia MK. Physicians' preparedness for bioterrorism and other public health priorities. Acad Emerg Med. 2006;13 (11):1238-1241.

4. Bremer R. Policy development in disaster preparedness and management: lessons learned from the January 2001 earthquake in Gujarat, India. Prehospital Disaster Med. 2003;18 (4): 372-384.

5. Levitin HW, Siegelson HJ, Dickinson S, et al. Decontamination of mass casualties: re-evaluating existing dogma. Prehospital Disaster Med. 2003;18 (3):200-207.

6. Covich JR, Parker CL, White VA. The practice community meets the ivory tower: a health department/academic partnership to improve public health preparedness. Public Health Rep. 2005;120 Suppl 1:84-90.

7. Gostin LO, Sapsin JW, Teret SP, et al. The Model State Emergency Health Powers Act: planning for and response to bioterrorism and naturally occurring infectious diseases. JAMA. 2002;288:622-628.

8. Roy N, Shah H, Patel V, Bagalkote H. Surgical and psychosocial outcomes in the rural injured: a follow-up study of the 2001 earthquake victims. Injury. 2005;36:927-934.

9. Kile JC, Skowronski S, Miller MD, et al. Impact of 2003 power outages on public health and emergency response. Prehospital Disaster Med. 2005;20:93-97.

10. Ashkenazi I, Kessel B, Khashan T, et al. Precision of in-hospital triage in mass-casualty incidents after terror attacks. Prehospital Disaster Med. 2006;21:20-23.

11. Hsu EB, Ma M, Lin FY, VanRooyen MJ, Burkle FM, Jr. Emergency medical assistance team response following Taiwan Chi-Chi earthquake. Prehospital Disaster Med. 2002;17:17-22.

12. Partridge R, King K, Proano L. Medical support for emergency relief workers after typhoon Sudal in Yap, Micronesia. Prehospital Disaster Med. 2006;21:215-219.

13. Perritt KR, Boal WL. Injuries and illnesses treated at the World Trade Center, 14 September-20 November 2001. Prehospital Disaster Med. 2005;20:177-183.

14. Public Health Security and Bioterrorism Preparedness and Response Act, Pub L No. 107-188, 116 Stat 682 (2002).

15. Nelson C, Lurie N, Wasserman J. Assessing public health emergency preparedness: concepts, tools, and challenges. Annu Rev Public Health. November 27, 2006. 
16. Collogan LK, Tuma F, Dolan-Sewell R, Borja S, Fleischman AR. Ethical issues pertaining to research in the aftermath of disaster. J Trauma Stress. 2004;17:363-372.

17. Progress and Promise in Research on Social and Cultural Dimensions of Health: A Research Agenda. Rockville, MD: Office of Behavioral and Social Science Research, National Institutes of Health; 2001.

18. Ready America campaign. Available at: http://www.ready.gov/americal index.html. Accessed March 20, 2007.

19. Dynes RR, Tierney KJ. Disasters, Collective Behavior, and Social Organization. Newark: University of Delaware Press; 1994.

20. Comfort LK. Risk, security, and disaster management. Annu Rev Political Sci. 2005;8:335-356.

21. Sundnes KO. Health disaster management: guidelines for evaluation and research in the Utstein style: executive summary. Task Force on Quality Control of Disaster Management. Prehospital Disaster Med. 1999; 14:43-52.

22. Cummins RO, Chamberlain D, Hazinski MF, et al. Recommended guidelines for reviewing, reporting, and conducting research on inhospital resuscitation: the In-Hospital "Utstein style." A statement for healthcare professionals from the American Heart Association, the
European Resuscitation Council, the Heart and Stroke Foundation of Canada, the Australian Resuscitation Council, and the Resuscitation Councils of Southern Africa. Circulation. 1997;95:2213-2239.

23. Ragin CC. The Comparative Method: Moving Beyond Qualitative and Quantitative Strategies. Berkeley: University of California Press; 1987.

24. Ragin CC. Fuzzy-Set Social Science. Chicago: University of Chicago Press; 2000

25. Yin RK. Applications of Case Study Research. Newbury Park, CA: Sage Publications; 1993.

26. Yin RK. Case Study Research: Design and Methods, 2nd ed. Thousand Oaks, CA: Sage Publications; 1994.

27. Hamel J, Dufour S, Fortin D. Case Study Methods. Newbury Park, CA: Sage Publications; 1993.

28. Lasker RD,New York Academy of Medicine. Committee on Medicine and Public Health. Medicine $\mathcal{E}$ Public Health: The Power of Collaboration. Chicago: Health Administration Press; 1998.

29. Starr P. The Social Transformation of American Medicine. New York: Basic Books; 1982.

30. Arnold JL. Disaster medicine in the 21st century: future hazards, vulnerabilities, and risk. Prehospital Disaster Med. 2002;17:3-11. 